\title{
Evaluation of Mix Proportions and Mechanical Properties of Normal and High-Strength Fibers Concrete
}

\author{
Imad R. Mustafa*, Omar Q. Aziz \\ Department of Civil Engineering, College of Engineering, Salahaddin University, Erbil, Kurdistan Region, Iraq
}

\author{
*Correspondence author: \\ Imad R. Mustafa, \\ Department of Civil \\ Engineering, College of \\ Engineering, Salahaddin \\ University, Erbil, Kurdistan \\ Region - F.R. Iraq \\ E-mail: emadbarzenjy@ \\ gmail.com
}

Received: 01 August 2019

Accepted: 03 September 2019

Published: 10 December 2019

\section{DOI}

10.25156/pti.V9n2y2019.pp202-207

\section{A B S T R A C T}

An experimental program is carried out to evaluate the mix design and mechanical properties of normal strength concrete (NSC) grade $40 \mathrm{MPa}$ and high-strength concrete grade 60 and $80 \mathrm{MPa}$. The study investigates using silica fume to produce high-strength concrete grade $80 \mathrm{MPa}$ and highlights the influence of adding steel fiber on the mechanical properties of normal and high-strength concrete. For NSC, the compressive strength is found at 7 and 28 days. While for higher strength concrete, the compressive strength is determined at 7,28 , and 56 days. The splitting tensile strength and flexural strength is determined at 28 days. Based on results, the specimens with $14 \%$ silica fume are higher compressive strength than the specimens with $10 \%$ silica fume by $21.8 \%$. The presence of steel fiber increased the compressive strength of normal and high-strength concrete at 7,28 , and 56 days curing ages with different percentage and the steel fiber has an important role in increasing the splitting tensile strength and flexural strength of normal and high-strength concrete.

Keywords: Compressive strength; Flexural strength; Silica fume; Splitting tensile strength; Steel fiber

\section{INTRODUCTION}

As a significant structure material, concrete has been generally utilized in structural designing applications, for example, building, extensions, and streets building, and the related trial investigation of the mechanical properties of cement is additionally fruitful (ASTM C150, 2016). The structure of cement blends includes assurance of the extents of the given constituent in particular, bond, fine totals, coarse totals, water, and admixture, assuming any, which would deliver concrete having indicated extents both in the new and solidified states with the most extreme by and large economy (ASTM C33, 2016 ). The goal of any blend proportioning strategy is to decide a fitting and practical mix of solid constituents that can be utilized for a first preliminary clump to create a sort of solid that is near what can accomplish a decent harmony between the different wanted properties of the solid at the most minimal conceivable expense. A blend proportioning technique just gives a beginning blend plan that should be pretty much adjusted to meet the ideal solid attributes. Notwithstanding the way that blend proportioning is as yet something of a workmanship, it is irrefutable that some basic logical standards can be utilized as a base for blend counts (ASTM C1240, 2016). High-quality cement (HSC) has a compressive quality more noteworthy than $55 \mathrm{MPa}$.
High-quality solid methods great scraped area, effect and cavitation opposition. Utilizing HSC in structures today would result in monetary favorable circumstances. Most utilizations of HSC to date have been in tall structures, long range extensions, and some unique structures. Real utilization of HSC in tall structures has been in segments and shear dividers, which brought about the diminishing of the dead weight of the structures and increment in the measure of the rental floor space in the lower stories (ACI-318, 2014). HSC dependably has a low water/ concrete proportion in the range of $0.20-0.45$. The utilization of high range water diminishing admixtures in HPC is fundamental to accomplish functionality. It is likewise discovered that the utilization of silica smolder (SF) as a strengthening cementitious material in HPC is indispensable if the ideal high quality is to be achieved (Mahadik et al., 2014). Blend extents for (HSC) are impacted by numerous components, including determined execution properties, locally accessible materials, nearby experience, individual inclinations, and cost. Pozzolans, for example, silica rage (SF), fly cinder, and metakaolin are presented as beneficial cementitious materials. These admixtures assume a significant job as micro fillers and help improve molecule pressing thickness of cementitious framework, rheological properties in crisp state, mechanical properties, and sturdiness (ASTM C1240, 2016). The utilization of silica 
rage in the creation of HSC has turned into a necessary case, due to a critical upgrade achieved on interfacial zone of bond paste- total. Silica rage comprises ultrafine $(<1 \mathrm{~lm})$ particles and expands the bond quality between concrete glue and total by making the interfacial zone progressively thick. It additionally assumes a significant job in expanding the mechanical qualities of cement in view of having a pozzolanic movement (combined impact of silica smoke and steel fiber). To improve properties of cement, another kind of cement known as fiber strengthened cement is presented. Fiber strengthened cement (FRC) is a relative new composite material wherein strands are presented in the grid as miniaturized scale support, to improve the malleable, splitting, and different properties of concrete (BS EN 12390-1, 2004). The fiber was utilized in cement to build the rigidity and improve different properties of cement. The fiber can keep up the auxiliary trustworthiness and cohesiveness in the material. It additionally can give break opposition and split control, improve the post-splitting, and others (ASTM 496, 2016).

\section{THE SIGNIFICANCE OF THE RESEARCH}

The present investigation has been aimed to better understanding of the mechanical properties of normal and high-strength concrete. Seventeen mix trails performed for normal and high-strength concrete grade 40, 60, and $80 \mathrm{MPa}$ and using silica fume to produce highstrength concrete grade $80 \mathrm{MPa}$. The study included the investigation of adding steel fiber to normal and highstrength concrete mixes to understand the influence of steel fiber on the mechanical properties of normal and high-strength concrete.

\section{METHODOLOGY}

- The mix design calculated according to ACI committee 318.

- Prepared materials and tested according to ASTM specification such as cement, fine and coarse aggregate, silica fume, super-plasticizer, steel fiber, and mixing water.

- Seventeen mix trails performed for normal and highstrength concrete, seven mix trails performed for normal strength concrete (NSC) grade $40 \mathrm{MPa}$, five mix trails prepared for high-strength concrete grade $60 \mathrm{MPa}$, and five mix trails prepared for high-strength concrete with silica fume grade $80 \mathrm{MPa}$.

- Compressive strength for NSC was determined at 7 and 28 days and for high-strength concrete at 7, 28, and 56 days, the splitting tensile strength and flexural strength were determined at 28 days.

\section{MATERIAL PROPERTIES}

\section{Review Stage}

The cement used throughout this work was Ordinary Portland Cement, CEM-I 42.5R MASS CEMENT, produced by Mass Cement Factory in Kurdistan. The physical and chemical properties of the cement are shown in Tables 1 and 2 and compared with ASTM C150 (ASTM C150, 2016).

\section{Fine Aggregate}

Normal sand was obtained from Aski-Kalak quarry, welldried and sieve analysis was performed. The sieve analysis of the used sand according to ASTM C33 (ASTM C33 2016) is shown in Figure 1.

\section{Coarse Aggregate}

The washed coarse aggregate was used the crushed with $9.5 \mathrm{~mm}$ maximum aggregate size. It was brought from Aski-Kalak area. The gravel was dried and any impurities were removed. The grading of coarse aggregate and ASTM C33 (ASTM C33 2016) limitations are shown in Table 3.

\section{Silica Fume}

The silica fume type MICRO SILICA SUPAFLO was used. The chemical and physical properties of micro silica are shown in Table 4 and compared with ASTM C1240 (ASTM C1240 2016).

\section{Steel Fibers}

Straight type of steel fibers was used with the percentage of $0.75 \%$ by volume of concrete. Table 5 shows the properties of steel fibers and Figure 2 shows shape of steel fiber.

Table 1: Physical properties of the cement

\begin{tabular}{lcl}
\hline Physical tests & Results & ASTM C150 \\
\hline Initial setting time & 165 & Not <45 min \\
Final setting time & 220 & Not more than 375 min \\
3-day compressive strength & 32.9 & $12.0 \mathrm{MPa}$, lower limit \\
7-day compressive strength & 40.1 & $19.0 \mathrm{MPa}$, lower limit \\
\hline
\end{tabular}

Table 2: Mechanical properties of the cement

\begin{tabular}{lcc}
\hline Material contents (\%) & Results & ASTM C150 \\
\hline Loss on ignition & 1.78 & 3.0 max \\
Insoluble materials & 0.68 & 0.75 max \\
$\mathrm{SiO}_{2}$ & 22.45 & \\
$\mathrm{CaO}$ & 65.34 & \\
$\mathrm{Al}_{2} \mathrm{O}_{3}$ & 4.68 & \\
$\mathrm{Fe}_{2} \mathrm{O}_{3}$ & 3.19 & 6.0 max \\
$\mathrm{MgO}_{\mathrm{SO}}$ & 1.26 & 3.0 max \\
$\mathrm{LSF}_{\mathrm{C}_{3} \mathrm{~A}}$ & 2.15 & \\
$\mathrm{C}_{3} \mathrm{~S}$ & 0.93 & \\
$\mathrm{C}_{2} \mathrm{~S}$ & 7.00 & \\
$\mathrm{C}_{4} \mathrm{AF}$ & 53.25 & \\
\hline
\end{tabular}




\section{Super-plasticizer}

Hyperplast PC200 is a high-performance concrete superplasticizer admixture based on polycarboxylic polymers with long chains specially designed to enable the water content of the concrete to perform more effectively. This effect can be used in high-strength concrete and flowable concrete mixes, to achieve highest concrete durability and performance.

\section{Mixing Water}

Ordinary drinking water was used for mixing and curing of all kinds of concrete. It was clean and free from injurious amounts of oil, organic materials, and other deleterious substances.

\section{EXPERIMENTAL PROGRAM}

\section{Mix Design}

The mix design calculated according to ACI committee 318, 2014 (ACI-318, 2014). The slump value will be fixed on $50-75 \mathrm{~mm}$.

Table 3: Grading of coarse aggregate and ASTM limitations

\begin{tabular}{lccc}
\hline Sieve $\mathrm{mm}$ & \% passing & \multicolumn{2}{c}{ ASTM limits } \\
\cline { 3 - 4 } & & Lower & Upper \\
\hline 12.5 & 100 & 100 & 100 \\
9.52 & 92.4 & 85 & 100 \\
4.76 & 20.7 & 10 & 30 \\
2.36 & 1.7 & 0 & 10 \\
1.18 & 0 & 0 & 5 \\
Bulk specific gravity (SSD) & & 2.76 & \\
\hline
\end{tabular}

Table 4: Chemical and physical properties of micro-silica fume

\begin{tabular}{lcc}
\hline Composition (\%) & Results & ASTM C1240 \\
\hline Loss on ignition & 0.70 & $6.0 \mathrm{max}$ \\
$\mathrm{SiO}_{2}$ & 92.55 & $85.0 \mathrm{~min}$ \\
$\mathrm{Al}_{2} \mathrm{O}_{3}$ & 0.57 & \\
$\mathrm{Fe}_{2} \mathrm{O}_{3}$ & 1.10 & \\
$\mathrm{CaO}$ & 0.21 & \\
$\mathrm{MgO}$ & 1.11 & \\
$\mathrm{SO}_{3}$ & 0.37 & \\
$\mathrm{Na}_{2} \mathrm{O}$ & 0.25 & \\
$\mathrm{H}_{2} \mathrm{O}$ & 1.22 & \\
$\mathrm{Color}$ & $W \mathrm{max}$ \\
Specific gravity & $2.6 \pm 0.1$ & \\
Fineness $\left(\mathrm{m}^{2} / \mathrm{kg}\right)$ & 23200 & $15,000 \mathrm{~min}$ \\
Bulk density $\left(\mathrm{kg} / \mathrm{m}^{3}\right)$ & $600 \pm 50$ & \\
\hline
\end{tabular}

Table 5: Properties of steel fibers

\begin{tabular}{lc}
\hline Property & Specifications \\
\hline Length & $40 \mathrm{~mm}$ \\
Diameter & $0.4 \mathrm{~mm}$ \\
Aspect ratio & 100 \\
Yield strength & $1250 \mathrm{MPa}$ \\
Modulus of elasticity & $210 \mathrm{GPa}$ \\
\hline
\end{tabular}

\section{Mix Proportion Details}

The experimental program included two stages. During the first stage, seven mix trails with and without steel fiber performed for NSC (grade $40 \mathrm{MPa}$ ) to investigate the most appropriate concrete mix proportion which gives the best mechanical properties such as compressive strength, splitting tensile strength, and flexural strength and to determine influence of steel fiber on mechanical properties of NSC, the compressive strength for NSC was found at 7 and 28 days, the splitting tensile strength and flexural strength were determined at 28 days. In the second stage, the high-strength concrete (HSC) (grade 60 and $80 \mathrm{MPa}$ ) was investigated, 10 mix trails prepared to investigate the mechanical properties of high-strength concrete with and without steel fibers, five mix trails prepared for high-strength concrete grade $60 \mathrm{MPa}$, and five mix trails prepared for high-strength concrete with silica fume for grade $80 \mathrm{MPa}$, the compressive strength for high-strength concrete was found at the age 7,28 , and 56 days, the splitting tensile strength and flexural strength were determined at 28 days. Based on the previous researches (Mahadik et al., 2014), the volume fraction of steel fiber of $0.75 \%$ was used. Detail of mix proportion is shown

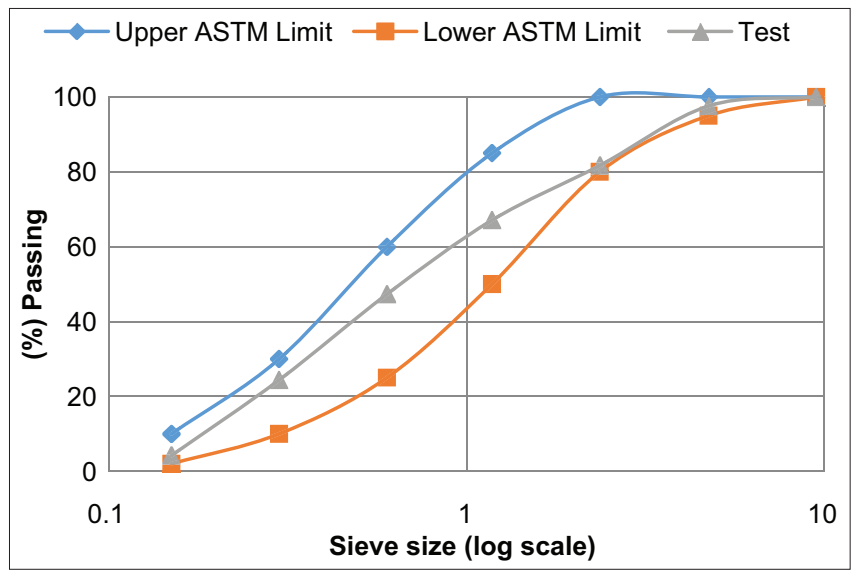

Figure 1: Sieve analysis of the sand according to ASTM

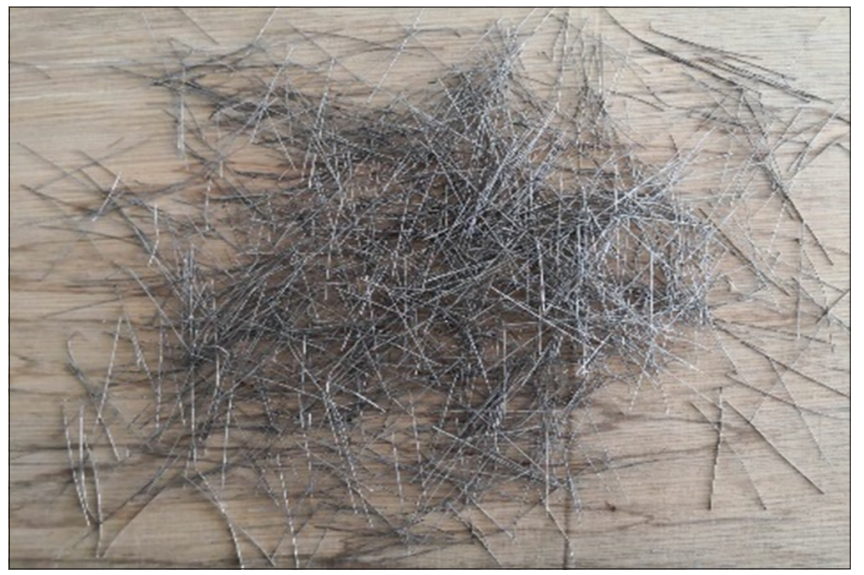

Figure 2: Steel fiber 
in Table 6. The replaced amount of cement by silica fume to produce high-strength concrete and improve the mechanical properties of concrete was used.

\section{Mixing Procedure}

A mechanical mixer with capacity of $0.1 \mathrm{~m}^{3}$ was used throughout the experimental works. The interior surface of the mixer was cleaned and moistened before feeding the materials.

For the NSC mixing, the procedure consists of adding mix dry sand and gravel to mixer about 3-5 min mixing then added half of water after that added the cement then the remain water gradually added with continuous mixing. For the high-strength concrete, mixing procedure consists of adding mix dry sand and gravel to mixer about 3-5 min mixing then added half of water after that pre-mixed silica fume and cement were added after 3-5 min, the premixed remain water and super-plasticizer added with continuous mixing. In the case of presence steel fiber, it was added after adding cementitious material with some extra time of mixing operation.

\section{Preparation of Testing Specimens}

Based on BS EN 12390-1, 2004, the compressive strength was carried out on cubic specimens with dimensions $100 \times 100 \times 100 \mathrm{~mm}$. For NSC, each mix trails six cubes were cast and each three cubes were tested at age 7 and 28 days. For high-strength concrete, nine cubes were cast and each three cubes were tested at age 7, 28, and 56 days, the compressive strength was taken as the average value of three specimens, Figure 3 shows cubes and testing machine.

Table 6: Mix proportion details

\begin{tabular}{llccccccc}
\hline Trails & Class & C & S & G & SF & SP/C & Fiber \% & W/B \\
\hline A-T1 & NSC & 1 & 1.2 & 1.8 & -- & -- & -- & 0.345 \\
A-T2 & NSC & 1 & 1.4 & 2.1 & -- & -- & -- & 0.36 \\
A-T3 & NSC & 1 & 1.6 & 2.4 & -- & -- & -- & 0.37 \\
A-T4 & NSC & 1 & 1.33 & 2.67 & -- & -- & -- & 0.37 \\
A-T5 & NSC & 1 & 2 & 3 & -- & -- & -- & 0.42 \\
A-T6 & NSC & 1 & 2.3 & 2.75 & -- & -- & -- & 0.44 \\
AT4F & NSC & 1 & 1.33 & 2.67 & -- & -- & 0.75 & 0.37 \\
B-T1 & HSC & 1 & 1.2 & 1.8 & -- & 0.005 & -- & 0.30 \\
B-T2 & HSC & 1 & 1.2 & 1.8 & -- & 0.005 & -- & 0.28 \\
B-T3 & HSC & 1 & 1 & 1.5 & -- & 0.005 & -- & 0.27 \\
B-T4 & HSC & 1 & 1.9 & 2.06 & -- & 0.005 & -- & 0.34 \\
B-T3F & HSC & 1 & 1.2 & 1.8 & & 0.005 & 0.75 & 0.28 \\
C-T1 & HSC & 1 & 1.8 & 2.3 & 0.11 & 0.022 & -- & 0.26 \\
C-T2 & HSC & 1 & 2.1 & 2.4 & 0.1 & 0.010 & -- & 0.34 \\
C-T3 & HSC & 1 & 1.5 & 2 & 0.12 & 0.023 & -- & 0.29 \\
C-T4 & HSC & 1 & 1.5 & 2.36 & 0.14 & 0.012 & -- & 0.28 \\
C-T4F & HSC & 1 & 1.5 & 2.36 & 0.14 & 0.012 & 0.75 & 0.28 \\
\hline
\end{tabular}

NSC: Normal strength concrete, HSC: High-strength concrete, C: Cement,

S: Sand, G: Gravel, SF: Silica fume, SP: Super-plasticizer, W: Water, B: Binder
The splitting tensile strength was conducted on cylinders with $100 \times 200 \mathrm{~mm}$ dimensions, the average of three specimens was taken; the test was carried out in accordance ASTM 496-04 (ASTM 496, 2016). Figure 4 shows cylinders and the testing machine.

The prisms with $75 \times 75 \times 350 \mathrm{~mm}$ were prepared for flexural strength tests. The flexural strength test was done according to ASTM C 78-94 (ASTM C78, 2016). The flexural strength was taken as the average value of three specimens. Figure 5 shows prisms and testing machine.

The curing condition by submerging in water tank then laid in the laboratory temperature and humidity.

\section{RESULTS AND DISCUSSION}

\section{Compressive Strength}

The compressive strength development at various curing ages for all types of concrete is presented in Table 7.
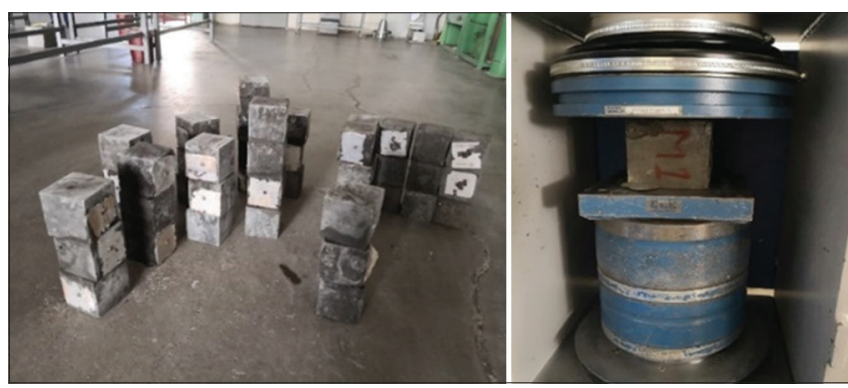

Figure 3: Cubes and compressive strength test machine

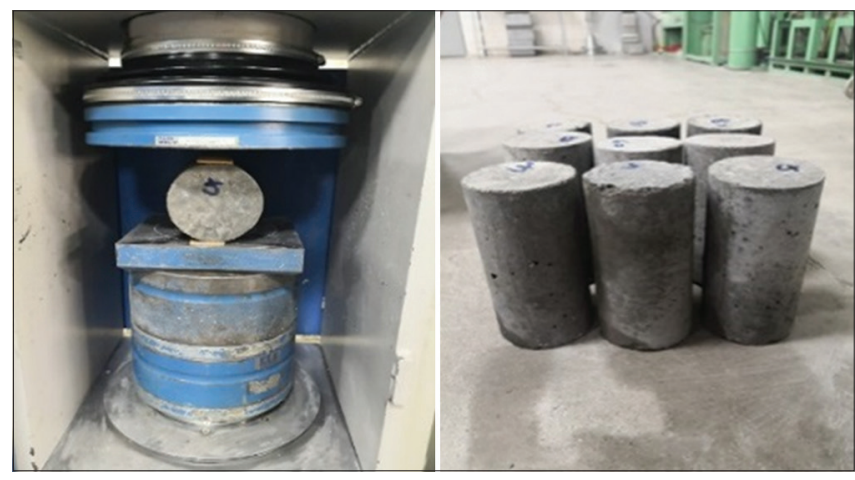

Figure 4: Cylinders and testing machine

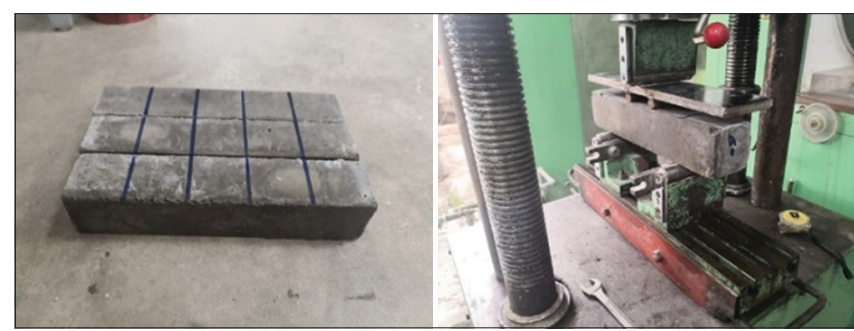

Figure 5: Prisms and testing machine 
All concrete specimen results demonstrated continuous increase in compressive strength with increase of curing age.

The NSC at 7 days curing age, significantly increased about $90 \%$ of target strength, the rate of increasing compressive strength decreases after 7 days, and the compressive strength for NSC reached to target strength at 28 days curing ages.

The compressive strength of high-strength concrete at 7 days curing age was increased with different percentage, the compressive strength for high-strength concrete continuously increased until 56 days, and the rate of increasing compressive strength after 28 days decreased, the high-strength concrete grade $80 \mathrm{MPa}$ reached to target strength at 56 days.

The super-plasticizer admixture was added to high-strength concrete to improve workability, the super-plasticizer should be added carefully because excess amount will produce segregation of the concrete and it will make the concrete weaker.

For high-strength concrete grade $80 \mathrm{MPa}$ with silica fume the compressive strength increased significantly, the specimens with $14 \%$ silica fume gave of higher compressive strength than the specimens with $10 \%$ silica fume by $21.8 \%$ because silica fume is very fine non crystalline material, adding silica fume in concrete to improves concrete compressive strength through two mechanisms that are Pozzolanic effect and microfiller effect also silica fume strengthens concrete by strengthening the bond between cement paste and aggregate.

Table 7: Average compressive strength test results

\begin{tabular}{lcccc}
\hline Trails & Steel fiber\% & \multicolumn{3}{c}{ Compressive strength $(\mathrm{MPa})$ at } \\
\cline { 3 - 5 } & & $\mathbf{7}$ days & 28 days & 56 days \\
\hline A-T1 & -- & 34.89 & 43.72 & -- \\
A-T2 & -- & 40.32 & 51.54 & -- \\
A-T3 & -- & 36.11 & 46.95 & -- \\
A-T4 & -- & 37.51 & 47.63 & -- \\
A-T5 & -- & 37.23 & 48.60 & -- \\
A-T6 & -- & 44.47 & 49.98 & -- \\
A-T4F & 0.75 & 50.92 & 55.13 & - \\
B-T1 & -- & 53.50 & 63.26 & 69.64 \\
B-T2 & -- & 56.48 & 64.41 & 69.42 \\
B-T3 & -- & 54.49 & 65.41 & 70.44 \\
B-T4 & -- & 53.98 & 67.82 & 71.67 \\
B-T3F & 0.75 & 68.2 & 72.23 & 75.81 \\
C-T1 & -- & 48.85 & 68.83 & 75.39 \\
C-T2 & -- & 43.94 & 66.86 & 70.72 \\
C-T3 & -- & 54.96 & 70.96 & 81.48 \\
C-T4 & -- & 57.56 & 77.56 & 86.14 \\
C-T4F & 0.75 & 69.61 & 84.27 & 90.31 \\
\hline
\end{tabular}

In the presence of steel fiber, the compressive strength increased by different percentage at 7,28 , and 56 days due to the confinement of the fiber reinforcement on the specimen and the steel fibers will effectively holds the microcracks in concrete mass. The compressive strength test results comparative with added steel fiber are presented in Table 8.

At 7 days curing age, the increasing percentage of compressive strength was $35.75 \%, 25.16 \%$, and $20.94 \%$ for grade 40, 60, and $80 \mathrm{MPa}$, respectively. At 28 days curing age, the percentage of the increased compressive strength was $15.74 \%, 10.43 \%$, and $8.65 \%$ for grade 40,60 , and 80 $\mathrm{MPa}$. The rate of increasing compressive strength at 56 days curing age decreased to $7.62 \%$ and $4.84 \%$ for 60 and 80 $\mathrm{MPa}$. Adding steel fiber by greater percentage will produce the workability problem. The advantage of the presence of silica fume with steel fiber is the silica fume decreased the workability and the unit weight of the fresh concrete similarly, the steel fibers negatively affect the workability but increased the unit weight of the concrete, the brittleness of concrete increased by adding of silica fume to concrete to get higher strengths, however, the use of steel fibers in concrete provides a ductile concrete structure and hence increases the energy absorption capacity of concrete also the combination of steel fiber and silica fume which distinction fibers in the mix and will create a strong bond between the fiber and the matrix.

\section{Splitting Tensile Strength}

The splitting tensile strength was determined at ages of 28 days for moist cured concrete specimens. The test results of the splitting tensile strength are reported in Table 9.

The splitting tensile strength becomes higher with the steel fiber inclusion. The percentage of increased splitting tensile

Table 8: Average compressive strength test results with and without steel fiber

\begin{tabular}{lcccc} 
Trails & Steel fiber\% & \multicolumn{3}{c}{ Compressive strength (MPa) at } \\
\cline { 3 - 5 } & & $\mathbf{7}$ days & $\mathbf{2 8}$ days & $\mathbf{5 6}$ days \\
\hline A-T4 & -- & 37.51 & 47.63 & -- \\
A-T4F & 0.75 & 50.92 & 55.13 & -- \\
B-T3 & -- & 54.49 & 65.41 & 70.44 \\
B-T3F & 0.75 & 68.2 & 72.23 & 75.81 \\
C-T4 & -- & 57.56 & 77.56 & 86.14 \\
C-T4F & 0.75 & 69.61 & 84.27 & 90.31 \\
\hline
\end{tabular}

Table 9: Average splitting tensile strength test results

\begin{tabular}{lcc}
\hline Trails & \multicolumn{2}{c}{ Splitting tensile strength $(\mathrm{MPa})$ at $\mathbf{2 8}$ days } \\
\cline { 2 - 3 } & Without steel fiber & With steel fiber \\
\hline A-T6 & 3.78 & 4.89 \\
B-T4 & 5.18 & 6.57 \\
C-T4 & 6.73 & 8.61 \\
\hline
\end{tabular}


Table 10: Average flexural strength test results

\begin{tabular}{lcc}
\hline Trails & \multicolumn{2}{c|}{ Flexural strength $(\mathrm{MPa})$ at $\mathbf{2 8}$ days } \\
\cline { 2 - 3 } & Without steel fiber & With steel fiber \\
\hline A-T6 & 6.69 & 7.73 \\
B-T4 & 8.65 & 10.05 \\
C-T4 & 10.28 & 11.78 \\
\hline
\end{tabular}

strength with steel fiber was $29.36 \%, 26.83 \%$, and $27.93 \%$ compared with same concrete trails specimens without steel fiber because presence of steel fiber would be good to transfer energy and restrain cracks initiation and propagation, also the presence of steel fiber in concrete specimens was changed brittle failure to ductile failure. Splitting tensile strength is also increased by replacing the amount of cement by silica fume. The combination of silica fume and steel fiber in the concrete mixes improved the capacity of cracking arresting.

\section{Flexural Strength}

The flexural strength of concrete specimens determined at age 28 days. The results of flexural strength tests are shown in Table 10.

The flexural strength capacity of concrete is about 10 $20 \%$ of the compressive strength of the concrete. The presence of steel fiber in the concrete increased the flexural strength. The percentage of the increased flexural strength of concrete with steel fiber was $15.55 \%, 16.18 \%$, and $14.59 \%$ compared with the same concrete trails specimens without steel fiber because fibers will effectively hold the microcracks in concrete mass and steel fiber usually reduces brittleness of concrete by providing post-cracking ductility and increases toughness. The presence of silica fume created significantly an increase in the flexural strength of the concrete. In previous work such as Mahadik et al., 2014, work, the percentage of increasing flexural strength with $0.75 \%$ steel fiber was $30.21 \%$ (Mahadik et al., 2014).

\section{CONCLUSIONS}

The results obtained in the study can be summarized as the following:

- The compressive strength of concrete increased with the increase in the curing age. The rate of increasing compressive strength by curing age was decreased after 7 days curing ages and the NSC reached the target strength at 28 days while the high-strength concrete with silica fume reached the target strength at 56 days curing age.

- The presence of silica fume increased the compressive strength of the concrete significantly, the specimens with 14\% silica fume are higher compressive strength than the specimens with $10 \%$ silica fume by $21.8 \%$.

- The presence of steel fiber increased the compressive strength of normal strength and high-strength concrete at 7,28 , and 56 days curing ages. The increased of compressive strength of NSC at 7 and 28 days was $35.75 \%$ and $15.74 \%$. The percentage of increased compressive strength for high-strength concrete grade $60 \mathrm{MPa}$ at 7,28 , and 56 days is $25.16 \%$, $10.43 \%$, and $7.62 \%$, respectively. For the highstrength concrete with silica fume, the percentage of increased compressive strength at 7,28, and 56 days is $20.94 \%, 8.65 \%$, and $4.84 \%$, respectively. These results indicate that the rate of increasing compressive strength by the presence of the steel fiber decreased with time.

- The steel fiber has an important role in increasing the splitting tensile strength of concrete, by adding steel fiber to the concrete mixes, the percentage of increasing splitting tensile strength was $29.36 \%$, $26.83 \%$, and $27.93 \%$ for the NSC grade $40 \mathrm{MPa}$ and high-strength concrete grade 60 and $80 \mathrm{MPa}$.

- The presence of steel fiber will restrain cracks initiation and propagation and changing mode failure of concrete from brittle failure to the ductile failure.

- The percentage of increasing the flexural strength by adding steel fiber was $15.55 \%, 16.18 \%$, and $14.59 \%$ for normal and high-strength concrete.

- The combination of silica fume and steel fiber in the concrete mixes improved the mechanical properties of concrete.

\section{REFERENCES}

American Concrete Institute. 2014. (ACl 318R) Building Code Requirements for Structural Concrete. American Concrete Institute, USA.

American Society for Testing and Materials 496-04 . 2016. Test Method for Splitting Tensile Strength of Cylindrical Concrete Specimens. American Society for Testing and Materials International, Pennsylvania, United States.

American Society for Testing and Materials C1240. 2016. Standard Specification for Silica Fume Used in Cementitious Mixtures. American Society for Testing and Materials International, Pennsylvania, United States.

American Society for Testing and Materials C150. 2016. Specification for Portland Cement. American Society for Testing and Materials International, Pennsylvania, United States.

American Society for Testing and Materials C33. 2016. Specification for Concrete Aggregates. American Society for Testing and Materials International, Pennsylvania, United States.

American Society for Testing and Materials C78-94. 2016. Test Method for Flexural Strength of Concrete (Using Simple Beam with Third-Point Loading). American Society for Testing and Materials International, Pennsylvania, United States.

British Standard, EN 12390-1. 2004. Testing Hardened Concrete: Shape, Dimensions and Other Requirements for Specimens and Moulds, Committee B/517/1. BSI, United Kingdom.

Mahadik, S.A., S. K. Kamane and A. C. Lande. 2014. Effect of steel fibers on compressive and flexural strength of concrete. Int. J. Adv. Struct. Geotech. Eng. 3(4): 388-392. 